\title{
The therapeutic effects of excimer laser coronary atherectomy therapy for in-stent restenosis chronic total occlusions
}

Hui Li ${ }^{1,2}$, Hu Ai ${ }^{1,2}$, Le Li ${ }^{1,2}$, Naixin Zheng ${ }^{1,2}$, Guodong Tang ${ }^{1,2}$, Guojian Yang ${ }^{1,2}$, Ying Zhao ${ }^{1,2}$, Fucheng Sun ${ }^{1,2}$ and Huiping Zhang ${ }^{1,2^{*}}$

\begin{abstract}
Objectives: To evaluate the safety and efficacy of excimer laser coronary atherectomy (ELCA) in patients with in-stent restenosis chronic total occlusions (ISR CTOs).

Background: ISR CTOs are a challenge in percutaneous coronary intervention (PCI). Although they can be treated by ELCA, limited data are available on the effects of ELCA treatment in these patients.

Methods: Fifty-nine consecutive patients underwent PCI for ISR CTOs at Beijing Hospital between December 2017 and September 2020. According to whether or not ELCA was performed, they were divided into two groups. Quantitative coronary angiography (QCA) analyses were performed routinely, including measurement of the minimal lumen diameter and calculation of the percentage diameter stenosis. The procedural success rate, the frequency of periprocedural complications, and the incidence rates of major adverse cardiac events (MACEs) over nine months were assessed. The primary endpoint in the study was the percentage diameter stenosis.

Results: Procedure success was achieved in most patients in both groups (75.9\%). Patients in the ELCA group exhibited a lower percentage diameter stenosis $(24.5 \pm 9.09 \mathrm{vs} .35 .1 \pm 18.6, p=0.048)$ and a larger minimal lumen diameter $(2.36 \pm 0.29 \mathrm{~mm}$ vs. $1.78 \pm 0.64 \mathrm{~mm}, \mathrm{p}<0.001)$ than those in the control group and the 9-month incidence rates of MACEs did not differ (9.5\% vs $15.8 \%, p=0.699)$.
\end{abstract}

Conclusions: This study demonstrated that ELCA may be a safe and effective technique in the treatment of ISR CTOs, and the use of ELCA can achieve good immediate angiographic results, as measured by QCA, without increasing periprocedural complications or the incidence rates of 9-month MACEs.

Keywords: Excimer laser coronary atherectomy, Chronic total occlusion, In-stent restenosis

*Correspondence: zhanghuipingbjh@sina.com

1 Peking University Fifth School of Clinical Medicine, Beijing, People's Republic of China

Full list of author information is available at the end of the article Institution at which the work was performed: Beijing Hospital, National Center of Gerontology; Institute of Geriatric Medicine, Chinese Academy of Medical Sciences.

\begin{abstract}
Introduction
Stent therapy remains the first-line treatment for patients with severe coronary heart disease. Despite improvements in stent design, pharmacotherapy, and the polymers used in modern drug-eluting stents (DESs), approximately $5-10 \%$ of patients will experience in-stent restenosis (ISR) during angiographic follow-up [1, 2]. ISR continues to pose a therapeutic challenge and can be classified as focal, diffuse (with or without involvement of the stent edge), and chronic total occlusion (CTO) based
\end{abstract}


on the results of angiography [3]. Due to the diffuse neointimal proliferation or neoatherosclerosis that may occur in the stents, the most severe ISR CTOs are more challenging to treat, and the outcomes of conventional treatments such as plain old balloon angioplasty (POBA), drug-coated balloon (DCB) angioplasty, and new stent implantations are usually unsatisfactory [4-6].

One treatment option is excimer laser coronary atherectomy (ELCA), which uses a xenon chloride laser generator to generate a $308 \mathrm{~nm}$ laser that can reduce plaque volume. ELCA has acceptable indications, including in the treatment of ISR lesions [7]. However, the outcomes of patients with ISR CTOs who have undergone ELCA treatment have not been previously described. Therefore, the aim of this study was to evaluate the therapeutic efficacy and safety of ELCA therapy in this population.

\section{Materials and methods Study population}

We started a retrospective and descriptive study, the clinical and angiographic records of consecutive patients who underwent percutaneous coronary intervention (PCI) for ISR CTO by experienced surgeons at Beijing Hospital between December 2017 and September 2020 were reviewed. The indications to perform PCI were stable angina with viable myocardium and acute coronary syndrome. Data were collected and recorded in a dedicated CTO registry. The study protocols were approved by the ethics committee of Beijing Hospital, the study was conducted in accordance with the Declaration of Helsinki, and all patients signed informed consent to undergo coronary angiography and the intervention procedure.

The inclusion criteria were as follows: patients must have met the criteria for the diagnosis of ISR, any previous stent implantation must have occurred more than six months before the study, the coronary angiography must have revealed diffuse hyperplasia in the stent, and the diameter of the lumen must have been narrowed by more than 50\% [8]. At the same time, the characteristics of the ISR lesions had to be consistent with the definition of CTO, the thrombolysis in myocardial infarction (TIMI) grade for forward blood flow must have been 0 , and the estimated time of occlusion had to exceed three months [9]. Estimation of the duration of occlusion was based on the time from the first onset of angina, previous history of myocardial infarction (MI) in the target vessel territory, or comparison with the results of a prior angiogram.

\section{Procedure and devices}

All of the angiographic images collected were archived in an electronic database; these images and the intervention procedures were reviewed for all patients. All procedures were performed via the radial or femoral route using a 6 $\mathrm{F}$ or $7 \mathrm{~F}$ sheath and guiding catheter (Medtronic, Santa Rosa, CA). Before the initiation of interventional therapy, all patients were treated with a loading dose of dual antiplatelet therapy that included acetylsalicylic acid $300 \mathrm{mg}$ (Bayer, Berlin, German) combined with clopidogrel (Sanofi, Paris, France) 300 mg or ticagrelor (AstraZeneca, Cambridge, UK) $180 \mathrm{mg}$. The administration of intraoperative anticoagulation therapy consisting of unfractionated heparin or bivalirudin (Salubris, Shenzhen, China) was at the discretion of the operators. In patients who did receive such therapy, the dosage of unfractionated heparin was 70-100 IU/kg administered intravenously, and 1,000 units of unfractionated heparin were infused every hour. Bivalirudin was administered intravenously at a loading dose of $0.75 \mathrm{mg} / \mathrm{kg}$, followed by continuous intravenous infusion at a dose of $1.75 \mathrm{mg} / \mathrm{kg} / \mathrm{h}$ until $2 \mathrm{~h}$ after the procedure. For patients with chronic kidney disease, the dosage was adjusted according to the creatinine clearance rate.

Antegrade or retrograde technology was used to guide the wire through the occluded lesions. Patients in the non-ELCA group were treated with balloons to expand the lumen at the site of the lesion; subsequently, different sizes of DCBs or DESs were deployed according to the diameter of the blood vessel.

A CVX-300 excimer laser generator (Spectranetics, Colorado, Springs, USA) and select laser catheters were used in the ELCA group for ablation treatment. The diameter of the laser catheter was selected at the discretion of the operators according to the reference vessel and generally did not exceed half of the reference blood vessel's diameter. During the laser ablation treatment, in strict accordance with the operating specifications, the advance speed of the laser catheter was controlled a rate of $1 \mathrm{~mm} / \mathrm{s}$, and the intravenous bolus of physiological saline was continuously injected at a speed of $1 \mathrm{~mL} / \mathrm{s}$. The bolus of contrast agent was avoided during the treatment. Following ELCA treatment and according to the angiography, different types of balloons were selected for further dilation. Most patients were treated with DCBs at the stented segment. For any coexisting proximal or distal lesions of the stents, new DESs were usually deployed.

\section{Laboratory and electrocardiographic analyses}

For all patients, the concentrations of troponin, creatine kinase, and low-density lipoprotein cholesterol (LDL-C) were determined before and 6-24 $\mathrm{h}$ after PCI, with subsequent serial measurements performed in case there was any relevant biomarker elevation or patient complaints. Twelve-lead electrocardiographs were obtained 
before and after PCI, before hospital discharge, and upon suspicion of acute ischemia.

\section{Quantitative coronary angiography (QCA) analysis}

QCA analysis was performed offline using Centricity Cardiology CA 1000 software version 2.0 (General Electric, USA). All measurements (baseline and final) were conducted according to the current standards, with the outer diameter of the contrast-filled catheter used as the calibration standard. The measurements included the length of the lesion before intervention, which consisted of the stented segment in addition to the $5 \mathrm{~mm}$ proximal and distal margins, the diameter of the reference vessel, the minimal lumen diameter (MLD), and the percentage diameter stenosis after the procedure. The percentage diameter stenosis was defined as follows: defined as an increase in cardiac troponin levels above the 99th percentile URL and symptom recurrence, with or without new ST-segment changes.

Procedural success was defined as final percentage diameter stenosis $\leq 30 \%$ in the presence of grade 3 TIMI flow, without in-hospital death, emergency coronary artery bypass graft (CABG) surgery, and/or the need for repeat $\mathrm{PCI}$ during the index hospitalization period. The Japan CTO (J-CTO) score was calculated for each lesion based on the occlusion length, stump morphology, presence of calcification, presence of tortuosity, and any prior attempt to open up the CTO [12].

\section{Data management and clinical event adjudication}

In-hospital adverse events were recorded until discharge from the hospital. The 9-month clinical follow-up data

([reference vessel diameter-MLD]/reference vessel diameter $) \times 100 \%$

For the measurement of the MLD, an angiographic sequence without vascular constriction was selected. Two independent researchers measured the image sequence and took the average value for later analysis.

\section{Endpoints and definitions}

The primary endpoint in the study was the percentage diameter stenosis, and the secondary endpoint was the 9-month incidence rates of major adverse cardiac events (MACEs), which were defined as events requiring hospitalization from MI, clinically driven target lesion revascularization (TLR) following the index PCI, and cardiac death. All clinical endpoints were defined according to the criteria of the Academic Research Consortium [10]. TLR was defined as any repeated percutaneous intervention or surgical bypass of the target lesion. Cardiac death was defined as death resulting from cardiovascular causes, including MI, heart failure, and sudden cardiac death, among others.

PCI-related MI was defined as type 4a MI according to the fourth universal definition of MI [11]. PCI-related MI occurring $\leq 48 \mathrm{~h}$ after the index procedure was arbitrarily defined as an elevation of cardiac troponin values $>5$ times that of the $99^{\text {th }}$ percentile upper reference limit (URL) in patients with normal baseline values, or a rise in cardiac troponin levels $>20 \%$ of the baseline value when it is exceeded the URL, and at least one of the following criteria: new electrocardiographic changes indicative of ischemia, development of new pathological Q waves, angiographic findings consistent with a procedural flowlimiting complication, such as coronary dissection, occlusion of a major epicardial artery or graft, a thrombotic side-branch occlusion, disruption of collateral flow, or distal embolization. During the follow-up period, MI was were obtained at visits to outpatient clinics or, if infeasible, by telephone follow-up and/or administration of a medical questionnaire.

\section{Statistical analyses}

All statistical analyses were conducted using Statistical Package for the Social Sciences (SPSS) 23.0 software (SPSS Inc, Chicago, IL). Continuous variables with a normal distribution are presented as the mean \pm SD, whereas those with a nonnormal distribution are presented as the median (interquartile range). Continuous variables were compared using independent-samples $t$-tests or nonparametric Mann-Whitney $U$ tests. Categorical data are presented as counts (n) and percentages, and compared with chi-square or Fisher's exact tests. All tests were twotailed, and values less than 0.05 were considered statistically significant.

\section{Results}

\section{Baseline clinical characteristics}

A total of 341 patients were diagnosed with ISR by angiography at Beijing Hospital; of these patients, 72 had CTOs confirmed by angiographic images and medical history. A total of 59 patients received PCI. According to whether ELCA was performed or not, the patients were divided into two groups, the ELCA group and the nonELCA group (Fig. 1).

There were no significant differences in the baseline clinical variables between the ELCA group and the nonELCA group (Table 1). Of the study population, $83 \%$ were male, and $56 \%$ were diagnosed with a previous MI. Most patients exhibited a normal left ventricular ejection fraction (LVEF) and normal kidney function. A total of 39\% of patients presented with acute coronary syndrome. 


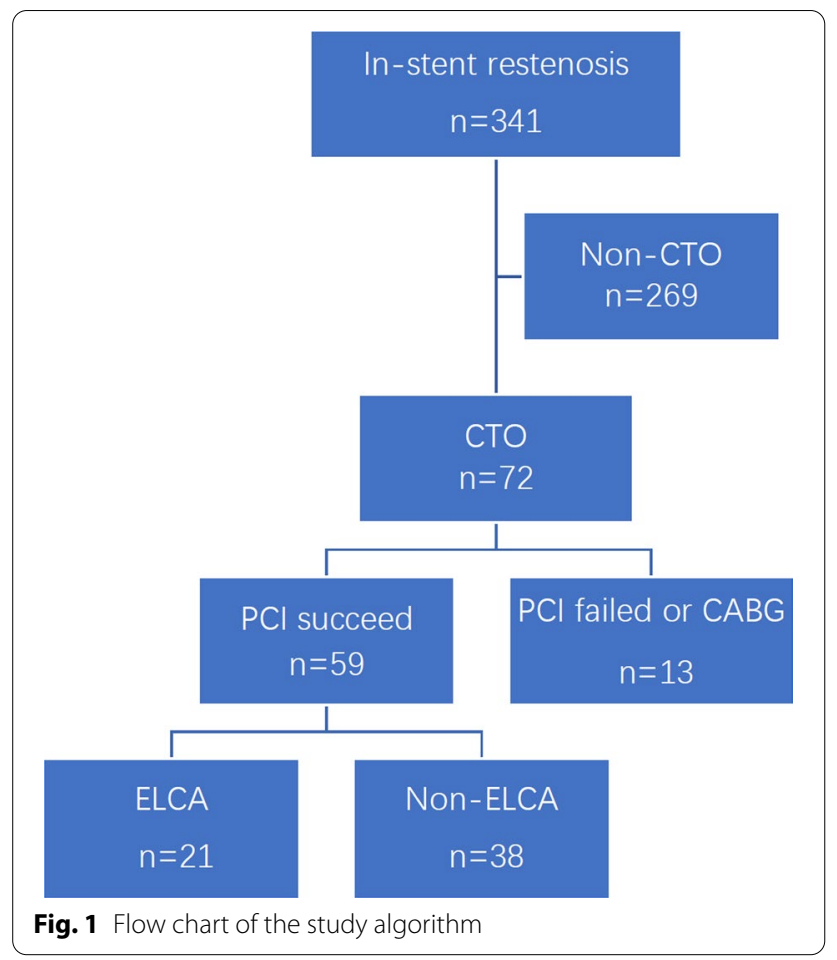

\section{Angiographic and procedural characteristics}

The angiographic and procedural characteristics of the two groups are summarized in Table 2. The ELCA group had a higher mean J-CTO score than the non-ELCA group ( $2.57 \pm 0.79$ vs. $1.67 \pm 0.70$, respectively; $\mathrm{p}=0.007)$, although the syntax score did not differ between groups $(p=0.141)$. Approximately $80 \%$ of the patients were treated with DCBs, although more DESs were used in the ELCA group than in the non-ELCA group $(61.9 \%$ vs. $34.2 \%$, respectively; $\mathrm{p}=0.040$ ). No significant differences were noted between groups in terms of the lesion location or lesion length, or the reference lumen diameter. DESs were used in $44.1 \%$ of the patients, although none of the stents were deployed in the previous stent segments. The ELCA group had a higher procedural success rate in terms of raw percentages, but there were no significant differences between groups. The percentage diameter stenosis was lower in the ELCA group than in the non-ELCA group (Fig. 2), whereas the MLD after treatment was larger. A typical patient who underwent ELCA is shown in Fig. 3.

\section{Peri-procedural complications and 9-month MACE outcomes}

The incidence of each peri-procedural complication is documented in Table 3. All procedures were conducted without the occurrence of major adverse events, including death, subacute closure, and target lesion revascularization (TLR) during the hospitalization period. However, coronary perforation did occur in two patients in the ELCA group, the classifications of which were Ellis class 2, which are defined as pericardial or myocardial blushing in the absence of an exit hole exceeding $1 \mathrm{~mm}$ in size [13] and no occurrence of tamponade requiring pericardiocentesis. For coronary

Table 1 Baseline clinical characteristics of the entire cohort

\begin{tabular}{|c|c|c|c|c|}
\hline & $\begin{array}{l}\text { Total } \\
n=59\end{array}$ & $\begin{array}{l}\text { ELCA group } \\
n=21\end{array}$ & $\begin{array}{l}\text { Non-ELCA group } \\
n=38\end{array}$ & $p$ value \\
\hline Age (years) & $65.1 \pm 10.1$ & $65.5 \pm 10.0$ & $65.0 \pm 10.3$ & 0.850 \\
\hline Male sex (\%) & $49(83.1)$ & $17(81.0)$ & $32(84.2)$ & 0.733 \\
\hline Hypertension (\%) & $40(67.8)$ & $14(66.7)$ & $26(68.4)$ & 0.890 \\
\hline Hyperlipidemia (\%) & $37(62.7)$ & $14(66.7)$ & $23(60.5)$ & 0.641 \\
\hline Diabetes mellitus (\%) & $29(49.2)$ & $12(57.1)$ & $17(44.7)$ & 0.361 \\
\hline Previous MI (\%) & $33(56.3)$ & $11(52.4)$ & $22(57.9)$ & 0.683 \\
\hline Previous CVA (\%) & $10(16.9)$ & $6(28.6)$ & $4(10.5)$ & 0.144 \\
\hline Current smoker (\%) & $34(57.6)$ & $15(71.4)$ & $19(50.0)$ & 0.111 \\
\hline $\mathrm{eGFR}\left(\mathrm{mL} / \mathrm{min} / 1.73 \mathrm{~m}^{2}\right)$ & $90.6 \pm 28.6$ & $98.4 \pm 26.3$ & $88.5 \pm 29.2$ & 0.341 \\
\hline LVEF \% & $59.5(49.3,60.0)$ & $49(45,63)$ & $60(52,60)$ & 0.627 \\
\hline LDL-C (mmol/L) & $2.03 \pm 0.68$ & $2.56 \pm 1.00$ & $1.97 \pm 0.57$ & 0.244 \\
\hline \multicolumn{5}{|l|}{ Clinical presentation } \\
\hline Stable angina (\%) & $36(61.0)$ & $14(66.7)$ & $22(57.9)$ & 0.508 \\
\hline ACS (\%) & $23(39.0)$ & $7(33.3)$ & $16(42.1)$ & 0.508 \\
\hline
\end{tabular}

Data are presented as $\mathrm{n}(\%)$ or mean \pm standard deviation or median (interquartile range)

MI, myocardial infarction; CVA, cerebrovascular accident; eGFR, estimated glomerular filtration rate; LVEF, left ventricular ejection fraction; LDL-C, low density lipoprotein-cholesterol; ACS, acute coronary syndrome 
Table 2 Angiographic and procedural characteristics of the patients

\begin{tabular}{|c|c|c|c|c|}
\hline & $\begin{array}{l}\text { Total } \\
\mathrm{n}=59\end{array}$ & $\begin{array}{l}\text { ELCA group } \\
n=21\end{array}$ & $\begin{array}{l}\text { Non-ELCA group } \\
n=38\end{array}$ & pvalue \\
\hline \multicolumn{5}{|l|}{ Lesion location } \\
\hline Left anterior descending (\%) & $27(45.8)$ & $14(66.7)$ & $13(34.2)$ & \\
\hline Left circumflex (\%) & $10(16.9)$ & $2(9.5)$ & $8(21.1)$ & \\
\hline Right coronary artery (\%) & $22(37.3)$ & $5(23.8)$ & $17(44.7)$ & 0.056 \\
\hline Multiple vessel disease (\%) & $55(93.2)$ & $20(95.2)$ & $35(92.1)$ & 1.000 \\
\hline Syntax score & $19.4 \pm 7.6$ & $21.9 \pm 3.3$ & $18.7 \pm 8.3$ & 0.141 \\
\hline J-CTO score & $1.87 \pm 0.81$ & $2.57 \pm 0.79$ & $1.67 \pm 0.70$ & 0.007 \\
\hline Treatment with DCB (\%) & $49(83.1)$ & $16(76.2)$ & $33(86.8)$ & 0.306 \\
\hline Treatment with DES (\%) & $26(44.1)$ & $13(61.9)$ & $13(34.2)$ & 0.040 \\
\hline IVUS & $12(20.3)$ & $5(23.8)$ & $7(18.4)$ & 0.739 \\
\hline OCT & $1(1.7)$ & $1(4.8)$ & $0(0)$ & 0.356 \\
\hline \multicolumn{5}{|l|}{ Before intervention } \\
\hline Lesion length (mm) & $33.5 \pm 11.3$ & $36.4 \pm 13.2$ & $32.7 \pm 10.7$ & 0.363 \\
\hline Reference lumen diameter (mm) & $2.79 \pm 0.54$ & $3.08 \pm 0.52$ & $2.72 \pm 0.52$ & 0.059 \\
\hline \multicolumn{5}{|l|}{ After intervention } \\
\hline Minimum lumen diameter (mm) & $1.90 \pm 0.63$ & $2.36 \pm 0.29$ & $1.78 \pm 0.64$ & $<0.001$ \\
\hline Percentage diameter stenosis & $32.9 \pm 17.5$ & $24.5 \pm 9.09$ & $35.1 \pm 18.6$ & 0.048 \\
\hline Procedure success (\%) & $44(75.9)$ & $18(85.7)$ & $26(70.3)$ & 0.187 \\
\hline Fluoroscopic time (min) & $37.3 \pm 20.9$ & $30.4 \pm 16.4$ & $39.2 \pm 21.7$ & 0.400 \\
\hline Contrast volume $(\mathrm{mL})$ & $230.4 \pm 58.4$ & $254.2 \pm 52.6$ & $223.7 \pm 58.8$ & 0.146 \\
\hline
\end{tabular}

Data are presented as $\mathrm{n}(\%)$ or mean \pm standard deviation or the median (interquartile range)

J-CTO score: Japan chronic total occlusion score; DCB: drug-coated balloon; DES: drug-eluting stent; IVUS: intravascular ultrasound; OCT: optical coherence tomography; PCl: percutaneous coronary intervention; MI: myocardial infarction

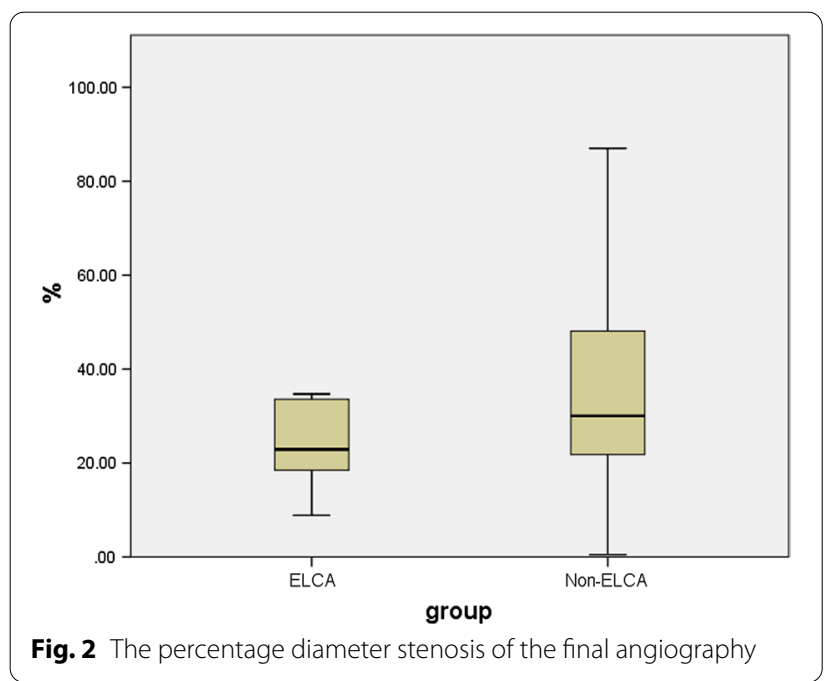

slow flow/ no re-flow complications that usually cause MI, the total peri-procedure complications did not exceed the sum of the individual complications. No cardiac death occurred, and no definite or probable stent thrombosis was recorded in any patient. A total of seven patients underwent TLR for binary restenosis, with no significant differences between both groups.

\section{Discussion}

The aim of the present study was to evaluate the immediate effects and 9-month outcomes of ELCA treatment in patients with ISR CTO. The main findings were as follows: (1) ELCA achieved good immediate angiographic results, as measured by QCA, without increasing the number of peri-procedural complications, including coronary perforation, coronary slow flow/no re-flow problems, and PCI-related MI. (2) ELCA did not alter the incidence of 9-month MACEs.

PCI with DESs is the current standard of care for the treatment of native coronary artery stenoses. However, the optimum percutaneous treatment strategy for patients presenting with ISR is still debated. Current studies have shown that for ISR, the use of DCBs can reduce the incidence of binary restenosis compared with that of POBA treatment [14]. DCBs offer the advantage of not requiring the implantation of an additional metallic layer when treating ISR, and they are recommended by the European Society of Cardiology and Chinese guidelines as the first-line treatment option [15, 16]. Because DCB technology has not yet received U.S. Food and Drug 


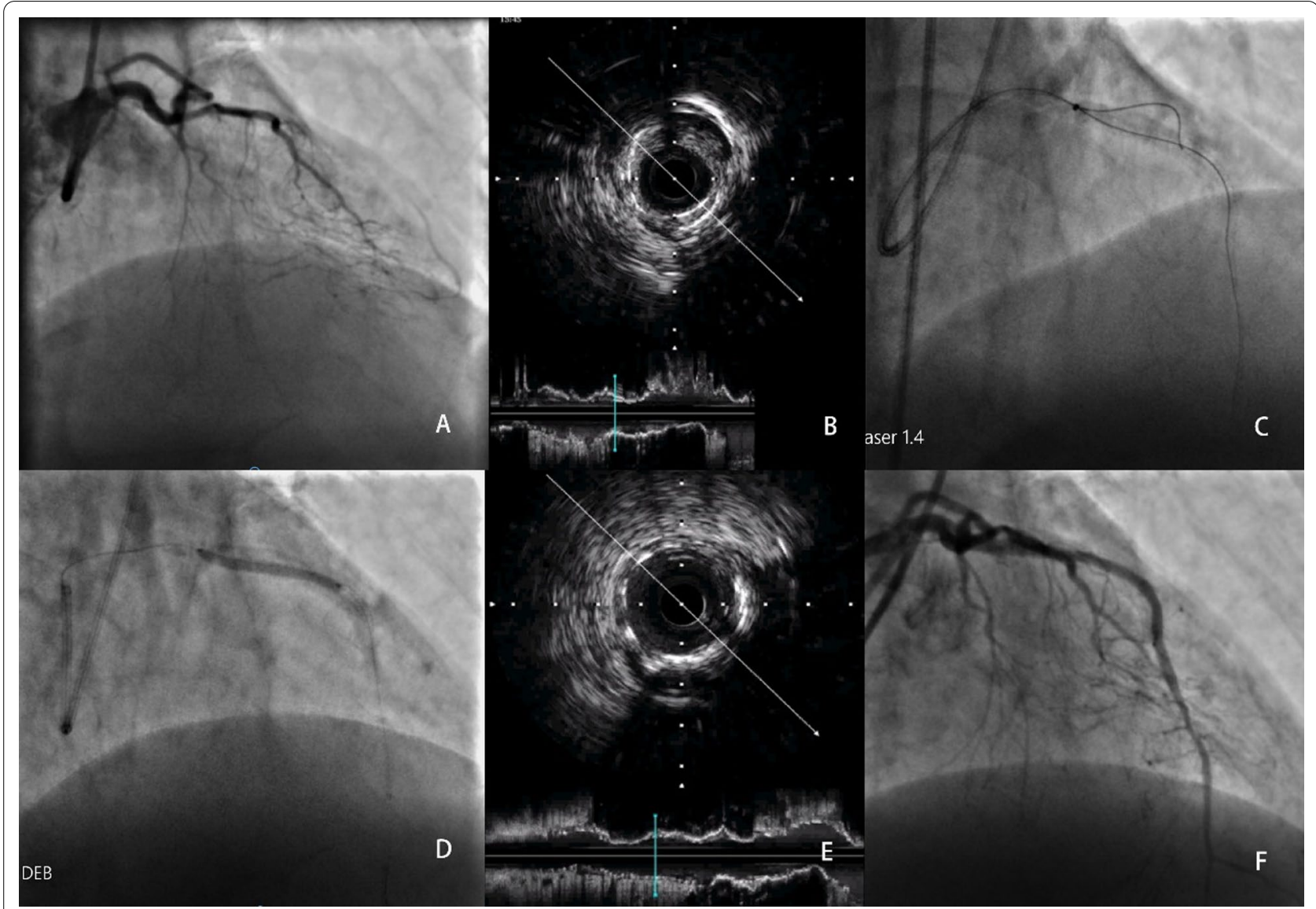

Fig. 3 A 55-year-old patient treated via ELCA and DCB. a Development of in-stent restenosis chronic total occlusion in the left anterior descending artery. b IVUS showing diffuse hyperplastic tissue in the stent segment. c ELCA conducted with a $1.4 \mathrm{~mm}$ catheter. d A 3.0-30 mm DCB deployed in the previous stent. e IVUS demonstrating the presence of mild residual hyperplastic tissue in the stent segment and lumen area. $\mathbf{f} T$ The final angiography of the artery post-procedure. ELCA = excimer laser coronary atherectomy; IVUS = intravascular ultrasound; DCB = drug-coated balloon

Table 3 Incidence of peri-procedural complications and 9-month MACEs

\begin{tabular}{|c|c|c|c|c|}
\hline & $\begin{array}{l}\text { Total } \\
n=59\end{array}$ & $\begin{array}{l}\text { ELCA group } \\
n=21\end{array}$ & $\begin{array}{l}\text { Non-ELCA group } \\
n=38\end{array}$ & p value \\
\hline Peri-procedural complications & $9(15.3)$ & $5(23.8)$ & $4(10.5)$ & 0.258 \\
\hline Coronary perforation & $2(3.4)$ & $2(9.5)$ & 0 & 0.123 \\
\hline Coronary slow flow/no flow & $4(6.6)$ & $2(9.5)$ & $2(5.3)$ & 0.812 \\
\hline PCl-related MI (\%) & $7(11.9)$ & $3(14.3)$ & $4(10.5)$ & 0.691 \\
\hline 9-month MACEs & $8(13.6)$ & $2(9.5)$ & $6(15.8)$ & 0.699 \\
\hline $\mathrm{Ml}$ & $1(1.7)$ & 0 & $1(2.6)$ & 1.000 \\
\hline TLR & $7(11.9)$ & $2(9.5)$ & $5(13.2)$ & 0.732 \\
\hline Cardiac death & 0 & 0 & 0 & NA \\
\hline Stent thrombosis & 0 & 0 & 0 & NA \\
\hline
\end{tabular}

Data are presented as $\mathrm{n}(\%)$

$\mathrm{PCl}$, percutaneous coronary intervention; MI, myocardial infarction; MACEs, major adverse cardiac events; TLR, target lesion revascularization

Administration approval for use in the coronary vasculature, repeated stent implantation and POBA are the regular choices in the USA [17].
Regardless of whether DCBs or DESs are used, it is impossible to truly remove the hyperplastic tissue or neoatherosclerosis present in the stent area. Unlike de 
novo lesions, this atherosclerotic plaque can expand and become redistributed. Due to the limitations of the original metallic stent structure, it is difficult to achieve sufficient expansion of ISR lesions through POBA. This inability to open up the coronary lumen reduces the therapeutic effects of the treatment. Therefore, it is common for a patient to experience binary restenosis within a short time following a procedure. When POBA is performed alone, the incidence of TLR at six months postprocedure is as high as $63.1 \%$ [18]. Lee et al. compared ISR CTOs and de novo CTOs that were mostly treated with DESs (>90\%); although the procedure success rate for treating ISR CTOs was higher because the previous stents could be used as a roadmap, the prognosis was worse, and the incidence of TLR was significantly higher $(14 \%$ vs $4.3 \%$, respectively; $\mathrm{p}<0.001)$ [19]. Therefore, in this type of situation, techniques such as ELCA for removing the hyperplastic tissue could be a promising therapeutic option.

ELCA mainly exerts photothermal, photochemical, and photomechanical effects that result in the removal of hyperplastic tissue. Both in vitro and in vivo experiments have revealed that ELCA treatment can break the chemical bonds of cellular molecules by forming microbubbles in the cells. This can completely remove the proliferated cells by reducing them into microparticles, resulting in a therapeutic effect through plaque volume reduction [7, 20]. Another possible mechanism that could explain the benefits of performing ELCA for ISR is that ISR develops as a result of stent under-expansion, as the stent is constrained by external layers of calcium. ELCA can ablate the tissue around the stent and improve its ability to expand. At baseline, all of the patients in this study were experiencing CTO; therefore, the percentage diameter stenosis may be the best indicator of the effects of PCI. In this study, the patients treated by ELCA achieved a lower percentage diameter stenosis, which reflected a "debulking effect" of the treatment. Furthermore, the patients in the ELCA group had a larger reference lumen diameter than that of the non-ELCA group, which indicated that those with greater hyperplastic tissue burden can achieve a larger MLD $(2.36 \pm 0.29 \mathrm{~mm}$ vs. $1.78 \pm 0.64 \mathrm{~mm}$, respectively; $\mathrm{p}<0.001)$.

The incidence rates of 9-month MACEs were similar in both groups, and most events were TLRs. The TLR rate was lower in the ELCA group than in the non-ELCA group ( $9.5 \%$ vs. $13.2 \%$, respectively), although the groups did not significantly differ. Early clinical studies have shown that for diffuse in-stent restenosis, ELCA combined with POBA can achieve satisfactory therapeutic effects similar to the outcome of rotational atherectomy combined with POBA, although the TLR rate at one year post-procedure remained as high as $26 \%$ [21]. Herein,
ELCA combined with DCB treatment for ISR CTOs resulted in a lower 9-month incidence rate of TLRs. However, due to an insufficient sample size, it was not possible to fully confirm the advantages of DEBs over POBA.

ELCA treatment can theoretically increase the total operation time; however, there were no significant differences in the fluoroscopic times or doses of contrast agents administered between the two groups. These two indicators were used instead of the overall operation time because these factors better reflect the extent of each patient's injury and the complexity of the procedures. Some possible reasons for this were considered. For example, ELCA treatment itself does not require much time, generally speaking; once the wire passes the CTO lesion, the entire procedure can be completed in approximately $15 \mathrm{~min}$, and ELCA treatment can reduce the amount of hyperplastic tissue in the area, which could reduce the subsequent balloon pre-dilation time.

In the present study, two patients (9.5\%) in the ELCA group developed coronary perforation without clinical sequelae; however, coronary perforation is one of the recognized serious complications of PCI. Danek et al. [22], in a study based on data from the PROGRESS-CTO registry, the rate of coronary perforation was much higher when ELCA was used than when it was not ( $7 \%$ vs. $2 \%$, respectively; $\mathrm{p}<0.009)$. Protty et al. [23] also reported that ELCA was associated with a higher coronary perforation rate (odds ratio: 2.18, 95\% confidence interval: 1.44-3.30) based on data from the British Cardiovascular Intervention Society database. For ISR CTO procedures, the wires may not remain in the true lumen as they are advanced in some segments; therefore, ELCA requires experienced operators, and operators must be cautious to avoid this kind of serious complication. Careful observation is recommended when a perforation does occur, as complications may develop over the course of several hours post-procedure. Laser light combined with simultaneous contrast injection can generate a powerful acoustic-mechanical effect, forming microbubbles that will increase the disruptive forces that result in an improved outcome, especially in cases of under-expanded stents $[24,25]$. However, this is not our recommendation, as it could result in a higher perforation rate and more serious types of perforations.

\section{Study limitations}

Some limitations of the present study should be noted. First, the study was retrospective in nature, so although the baseline clinical characteristics of the two groups completely matched, there may be some confounding factors that were not considered. Second, the angiographic images were analyzed by QCA analysis instead 
of more precise intracoronary imaging, such as IVUS or optical coherence tomography; this was because less than $30 \%$ of the included patients had those techniques applied during the intracoronary imaging. Third, this study is based on a small sample from a single center with a short time follow-up period; therefore, future studies with larger sample sizes and assessments of long-term prognosis are warranted. Fourth, the study population was strictly selected; thus, the results should be extrapolated with caution. Fifth, an undeniable learning curve was present when performing ELCA across subsequent cases. The strategy and technique for ISR CTOs conducted in a single center might not adequately reflect the outcomes of patients treated in other institutions. Finally, routine angiographic followup in patients who underwent PCI was not absolutely required in daily practice, which might have potentially induced a bias that affected the TLR rate.

\section{Conclusions}

The results of this study demonstrated that ELCA may be an effective treatment for ISR CTOs. It can significantly improve the immediate angiographic effects without increasing the occurrence of peri-procedural complications or the incidence rates of 9-month MACEs.

\begin{abstract}
Abbreviations
ACS: Acute coronary syndrome; CABG: Coronary artery bypass graft; CTO: Chronic total occlusion; CVA: Cerebrovascular accident; DCB: Drug-coated balIoon; DES: Drug-eluting stent; eGFR: Estimated glomerular filtration rate; ELCA: Excimer laser coronary atherectomy; ISR: In-stent restenosis; IVUS: Intravascular ultrasound; LDL-C: Low-density lipoprotein cholesterol; LVEF: Left ventricular ejection fraction; MACE: Major adverse cardiac event; MI: Myocardial infarction; MLD: Minimal lumen diameter; OCT: Optical coherence tomography; PCI: Percutaneous coronary intervention; POBA: Plain old balloon angioplasty; QCA: Quantitative coronary angiography; TIMI: Thrombolysis in myocardial infarction; TLR: Target lesion revascularization; URL: Upper reference limit.
\end{abstract}

\section{Acknowledgements}

Not applicable.

\section{Authors' contributions}

Study conception and design: HL, FCS, HPZ. Acquisition of data: LL, NXZ, GJY, GDT. Analysis and interpretation of data (e.g., statistical analysis, computational analysis): HL, HA, YZ. Writing, review, and/or revision of the manuscript: $\mathrm{HL}$, HPZ, FCS. Study supervision: FCS, HPZ. All authors have read and approved the manuscript.

\section{Funding}

Hui Li received funding from Beijing hospital (BJ-2019-156), the funding bodies played no role in collection, analysis, and interpretation of the data and in writing the manuscript.

\section{Availability of data and materials}

All data analyzed during the current study are available from the corresponding author upon reasonable request.

\section{Declarations}

\section{Ethics approval and consent to participate}

The study was approved by the ethics committee of Beijing Hospital, and all patients signed informed consent to undergo coronary angiography and the intervention procedure. Because the study was retrospective, we were unable to obtain informed consent from those patients in whom MACEs occurred, we also obtained informed consent waiver from the same ethics committee.

\section{Consent for publication}

The patient of Fig. 3 signed informed consent to the publishment of his images.

\section{Competing interests}

The authors declare that there is no competing interests.

\section{Author details}

${ }^{1}$ Peking University Fifth School of Clinical Medicine, Beijing, People's Republic of China. ${ }^{2}$ Cardiology Department, Beijing Hospital, National Center of Gerontology, Beijing, People's Republic of China.

Received: 15 June 2021 Accepted: 12 Auqust 2021

Published online: 18 August 2021

\section{References}

1. Bønaa KH, Mannsverk J, Wiseth R, Aaberge L, Myreng Y, Nygård O, et al. Drug-eluting or bare-metal stents for coronary artery disease. N Engl J Med. 2016. https://doi.org/10.1056/NEJMoa1607991.

2. Byrne RA, Sarafoff N, Kastrati A, Schömig A. Drug-eluting stents in percutaneous coronary intervention: a benefit-risk assessment. Drug Saf. 2009. https://doi.org/10.2165/11316500-000000000-00000.

3. Mehran R, Dangas G, Abizaid AS, Mintz GS, Lansky AJ, Satler LF, et al. Angiographic patterns of in-stent restenosis: classification and implications for long-term outcome. Circulation. 1999. https://doi.org/10.1161/ 01.cir.100.18.1872.

4. Gong ML, Mao Y, Liu JH. Long-term outcomes of percutaneous coronary intervention for in-stent chronic total occlusion. Chin Med J (Engl). 2020. https://doi.org/10.1097/CM9.0000000000001289.

5. Christopoulos G, Karmpaliotis D, Alaswad K, Lombardi WL, Grantham JA, Rangan BV, et al. The efficacy of "hybrid" percutaneous coronary intervention in chronic total occlusions caused by in-stent restenosis: insights from a US multicenter registry. Catheter Cardiovasc Interv. 2014. https:// doi.org/10.1002/ccd.25465.

6. Azzalini L, Dautov R, Ojeda S, Benincasa S, Bellini B, Giannini F, et al. Procedural and long-term outcomes of percutaneous coronary intervention for in-stent chronic total occlusion. JACC Cardiovasc Interv. 2017. https:// doi.org/10.1016/j.jcin.2017.01.047.

7. Tsutsui RS, Sammour Y, Kalra A, Reed G, Krishnaswamy A, Ellis S, et al. Excimer laser atherectomy in percutaneous coronary intervention: a contemporary review. Cardiovasc Revasc Med. 2021. https://doi.org/10. 1016/j.carrev.2020.10.016.

8. Cutlip DE, Windecker S, Mehran R, Boam A, Cohen DJ, van Es GA, et al. Clinical end points in coronary stent trials: a case for standardized definitions. Circulation. 2007. https://doi.org/10.1161/CIRCULATIONAHA.106. 685313.

9. Stone GW, Reifart NJ, Moussa I, Hoye A, Cox DA, Colombo A, et al. Percutaneous recanalization of chronically occluded coronary arteries: a consensus document: part II. Circulation. 2005. https://doi.org/10.1161/ CIRCULATIONAHA.105.583716.

10. Garcia-Garcia HM, McFadden EP, Farb A, Mehran R, Stone GW, Spertus J, et al. Standardized end point definitions for coronary intervention trials: the academic research consortium-2 consensus document. Circulation. 2018. https://doi.org/10.1161/CIRCULATIONAHA.117.029289.

11. Thygesen K, Alpert JS, Jaffe AS, Chaitman BR, Bax JJ, Morrow DA, et al. Fourth universal definition of myocardial infarction (2018). J Am Coll Cardiol. 2018. https://doi.org/10.1016/j.jacc.2018.08.1038.

12. Morino Y, Kimura T, Hayashi Y, Muramatsu T, Ochiai M, Noguchi Y, et al. Inhospital outcomes of contemporary percutaneous coronary intervention 
in patients with chronic total occlusion insights from the J-CTO Registry (Multicenter CTO Registry in Japan). JACC Cardiovasc Interv. 2010. https:// doi.org/10.1016/j.jcin.2009.10.029.

13. Ellis SG, Ajluni S, Arnold AZ, Popma JJ, Bittl JA, Eigler NL, et al. Increased coronary perforation in the new device era. Incidence, classification, management, and outcome. Circulation. 1994. https://doi.org/10.1161/ 01.cir.90.6.2725.

14. Rittger $H$, Brachmann J, Sinha AM, Waliszewski M, Ohlow M, Brugger A, et al. A randomized, multicenter, single-blinded trial comparing paclitaxel-coated balloon angioplasty with plain balloon angioplasty in drug-eluting stent restenosis: the PEPCAD-DES study. J Am Coll Cardiol. 2012. https://doi.org/10.1016/j.jacc.2012.01.015.

15. Xu B, Gao R, Wang J, Yang Y, Chen S, Liu B, et al. A prospective, multicenter, randomized trial of paclitaxel-coated balloon versus paclitaxeleluting stent for the treatment of drug-eluting stent in-stent restenosis: results from the PEPCAD China ISR trial. JACC Cardiovasc Interv. 2014. https://doi.org/10.1016/j.jcin.2013.08.011.

16. Neumann FJ, Sousa-Uva M, Ahlsson A, Alfonso F, Banning AP, Benedetto $U$, et al. ESC/EACTS guidelines on myocardial revascularization. Eur Heart J. 2018. https://doi.org/10.1093/eurheartj/ehy394.

17. Moussa ID, Mohananey D, Saucedo J, Stone GW, Simonton C. Trends and outcomes of restenosis after coronary stent implantation in the United States. J Am Coll Cardiol. 2020. https://doi.org/10.1016/j.jacc.2020.08.002.

18. Waksman R, White RL, Chan RC, Bass BG, Geirlach L, Mintz GS, et al. Intracoronary $\gamma$-radiation therapy after angioplasty inhibits recurrence in patients with in-stent restenosis. Circulation. 2000. https://doi.org/10. 1161/01.cir.101.18.2165.

19. Lee $\mathrm{SH}$, Cho JY, Kim JS, Lee HJ, Yang JH, Park JH, et al. A comparison of procedural success rate and long-term clinical outcomes between in-stent restenosis chronic total occlusion and de novo chronic total occlusion using multicenter registry data. Clin Res Cardiol. 2020. https:// doi.org/10.1007/s00392-019-01550-7.
20. Rawlins J, Talwar S, Green M, O'Kane P. Optical coherence tomography following percutaneous coronary intervention with Excimer laser coronary atherectomy. Cardiovasc Revasc Med. 2014. https://doi.org/10.1016/j. carrev.2013.10.002.

21. Mehran R, Dangas G, Mintz GS, Waksman R, Abizaid A, Satler LF, et al. Treatment of in-stent restenosis with excimer laser coronary angioplasty versus rotational atherectomy comparative mechanisms and results. Circulation. 2000. https://doi.org/10.1161/01.cir.101.21.2484.

22. Danek BA, Karatasakis A, Tajti P, Sandoval Y, Karmpaliotis D, Alaswad K, et al. Incidence, treatment, and outcomes of coronary perforation during chronic total occlusion percutaneous coronary intervention. Am J Cardiol. 2017. https://doi.org/10.1016/j.amjcard.2017.07.010.

23. Protty MB, Hussain HI, Gallagher S, Al-Raisi S, Aldalati O, Farooq V, et al. Excimer laser coronary atherectomy during complex PCl: an analysis of 1,471 laser cases from the British Cardiovascular Intervention Society database. Catheter Cardiovasc Interv. 2021. https://doi.org/10.1002/ccd. 29251.

24. Karacsonyi J, Danek BA, Karatasakis A, Ungi I, Banerjee S, Brilakis ES. Laser coronary atherectomy during contrast injection for treating an underexpanded stent. JACC Cardiovasc Interv. 2016. https://doi.org/10.1016/j.jcin. 2016.04.040.

25. Ashikaga T, Yoshikawa S, Isobe M. The effectiveness of excimer laser coronary atherectomy with contrast medium for underexpanded stent: the findings of optical frequency domain imaging. Catheter Cardiovasc Interv. 2015. https://doi.org/10.1002/ccd.25915.

\section{Publisher's Note}

Springer Nature remains neutral with regard to jurisdictional claims in published maps and institutional affiliations.
Ready to submit your research? Choose BMC and benefit from:

- fast, convenient online submission

- thorough peer review by experienced researchers in your field

- rapid publication on acceptance

- support for research data, including large and complex data types

- gold Open Access which fosters wider collaboration and increased citations

- maximum visibility for your research: over $100 \mathrm{M}$ website views per year

At BMC, research is always in progress.

Learn more biomedcentral.com/submissions 